\title{
International social work placements: What happens when your government tells you to come home?
}

\author{
Lee John Henley', Kora Deverick², Kathryn Hay²
}

\begin{abstract}
This article focuses on an international social work placement undertaken in Battambang, Cambodia. The article demonstrates the importance of joint work between university, student and host agency in designing clear tasks to be completed. The student and field educator returned home during this placement due to the impact of Covid-19. The article describes what changes were made to ensure the placement was able to continue, resulting in successful outcomes and learning achieved. Learning and reflections are provided by the student, Massey University and the field educator.
\end{abstract}

KEYWORDS: Overseas placement; student placement; field education; Covid-19
${ }^{1}$ Children's Future International, Cambodia

${ }^{1}$ Massey University, Aotearoa New Zealand

\section{Introduction}

Social work students feel better prepared for practice after applying formal learning to the practical experience of a placement (Cooner, 2010; Peterson, 2014; Wehbi, 2011). This article focuses on an international social work placement in Battambang, Cambodia, for a final-year Master of Applied Social Work student studying at Massey University, Aotearoa New Zealand. The host NGO has an interest in developing staff capabilities and reducing service dependency via case management pathways (Henley et al., 2019 a, b; Save The Children International, 2019) and uses a "knowledge development and flow" approach to placement planning (Henley, Lowe, Henley, Munro, 2019a). This requires a week-to-week task plan to be agreed by the student, university and host NGO before the placement begins.

The first part of this article gives background and context to the placement NGO. It then defines the placement planning approach. The impact of Covid-19 on the placement is discussed. Finally, responses to ensure the student completed their placement and delivered the important pieces of work along with reflections and future thoughts are presented.

\section{Background to the placement NGO}

Children's Future International (CFI) is situated in Ek Phnom, a rural and extremely poor area, approximately $8 \mathrm{~km}$ north of Battambang, Cambodia. It was founded in 2009 by two educators who witnessed what they considered to be preventable human rights issues. CFI was originally a Residential Care Institution (RCI) and now provides community-based holistic services to children and their families, and supports RCIs to reintegrate children and young people $(\mathrm{C} / \mathrm{Yp})$ back to family-based care. CFI provides a range of programmes, including social work, supplementary educational support and career development to C/Yp aged 5-21 years. These services are delivered, utilising a results-driven approach, in a community with untreated
AOTEAROA NEW ZEALAND SOCIAL WORK 32(2), 55-64.

CORRESPONDENCE TO: Lee John Henley lee@childrensfuture.org 
trauma from the Khmer Rouge genocide, poverty, malnutrition, unsafe migration, and exploitative experiences such as child labour, physical and sexual abuse, underage sex work and neglect. Using modern social work and educational approaches, CFI supports families to break the cycle of poverty. CFI's services reduce risks regarding child protection and unsafe migration for some of the most resource-poor and vulnerable children in Cambodia, and their families (CFI, 2019).

CFI has a particular interest in reducing service dependency, an often unrecognised concern in a Global South context (Henley et al., 2019a). CFI addresses this in several ways, the main one being a robust case management pathway focused on early exit planning and shorter-term interventions (Save the Children International, 2019). All services are delivered by Khmer staff, the organisation employs only two overseas staff from a total of 39 employees. All operational decision making is undertaken in Cambodia, with board members sitting in America, Europe and Australia. CFI is working towards a sustainable future where the organisation is fully led by Khmer staff.

\section{Social work in a developing context}

Social work in a developing context such as Cambodia, is an entirely different environment from Aotearoa New Zealand social work. Key differences include developing systems of social welfare and child protection, so vulnerable communities rely heavily on NGOs. While many NGOs are largely filling this gap to support vulnerable C/Yp, the legalities lie with local authorities and the Department of Social Affairs, Veterans and Youth Rehabilitation (DoSVY). While CFI works in partnership with local government, they receive no funding from this source and are reliant on grants and donations. Social work in Cambodia is an emerging profession, formal training programmes are a recent development and understanding of child protection is nascent. Para-social work is common as there are few qualified workers in communes or villages and varied levels of basic training (Fronek, Common, Smith Rotabi, \& Statham, 2019). Societal structure is heavily grounded in communities and a collective society approach.

\section{Placement planning}

A placement at CFI is a contributory one. Students are required to be high performing and confident and the experience of having travelled to or lived in a Global South context is preferred. Students lead a number of pieces of work and are expected to make a valuable contribution to developing systems and practice. In return, they receive weekly supervision, an opportunity to develop their research-led service development skills and a free Khmer home-cooked lunch daily! CFI's social work trainee was the fourth overseas student to undertake a placement at CFI. The field educator (FE) studied at Massey and has an ongoing relationship with this institution. Before the student left Aotearoa New Zealand, there were several meetings between them, Massey and CFI. These meetings achieved important aims: compatibility and suitability were checked, and a shared understanding of placement expectations and outcomes was ensured. These meetings produced a jointly agreed work plan as presented in Table 1.

These tasks were important for the NGO's development and provided excellent opportunities for the student to engage in research-led development work as well as demonstrate social work competencies. It was expected the plan would change slightly throughout the placement although no one could have predicted the severity of change that eventuated.

\section{Impact of and response to COVID-19}

Coronavirus (Covid-19) is an infectious disease caused by a newly discovered coronavirus (World Health Organisation, 2020). The first real signs of changes from Covid-19 being present in the local 


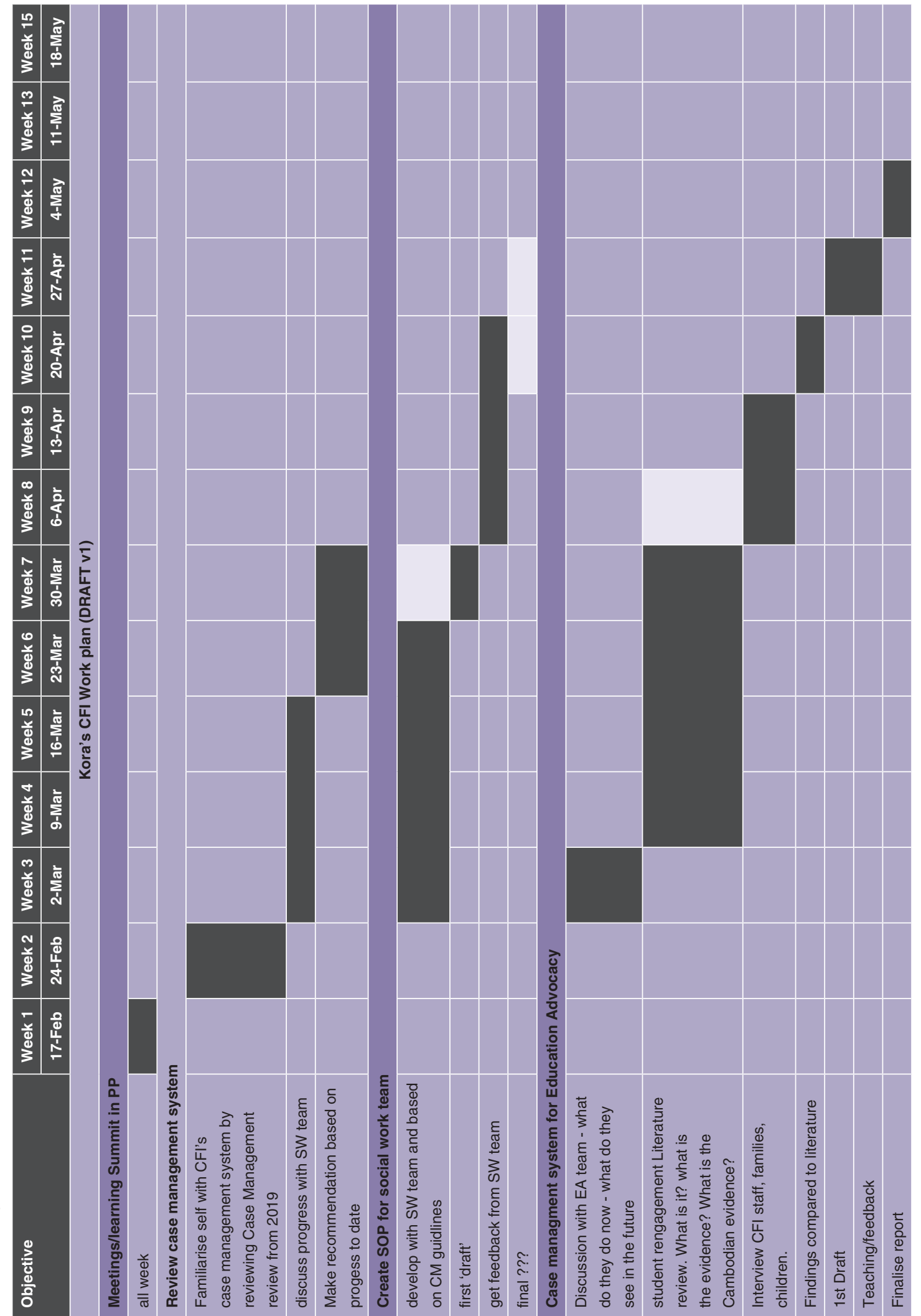




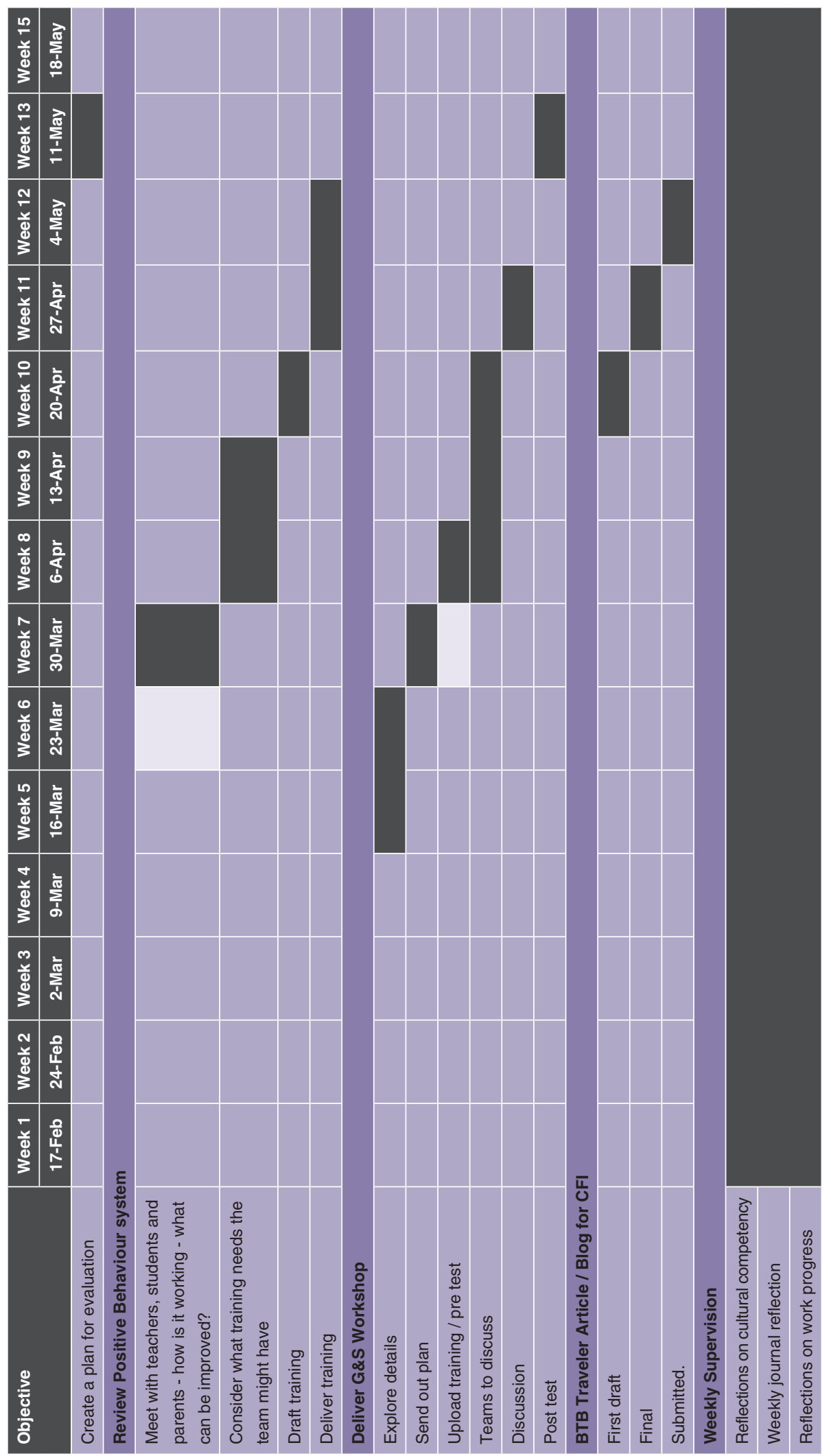


environment took place around the fifth week of the placement, as local support networks and services, such as restaurants and bars, started to close. While sounding trivial, this heralded an event far from normal. Shortly afterwards, all schools in Cambodia were directed to close. The student and FE had received warnings and advice from a number of sources, including Massey University, the Aotearoa New Zealand government and their families. Finally, given the advice of the government, the student decided to return to Aotearoa New Zealand. She packed up and left within two days amidst cancelled flights, tense travelers and an almost full A380-800 packed with only New Zealanders.

CFI, at the same time, prepared for a change in working practices. All staff were directed to work at home and social workers identified high-risk children to be contacted regularly. As schools were closed, these children would be home too. Local authorities and families were trained on social distancing, virus symptoms and effective handwashing. Teachers at CFI's school developed worksheets for C/Yp and the NGO went into lockdown. The FE also returned to Aotearoa New Zealand at this point. On the day of the flight home, all other flights were cancelled from Siem Reap airport, making this a "just in time" departure.

The change in location for the student and FE, and the whole NGO now working remotely required planned tasks to be reconsidered. Thankfully, the majority of the pre-planned tasks were still suitable for completion, albeit with some major adjustments, from outside of Cambodia. Supervision became a relationship maintained via Messenger voice calls, this was more of a continuation than a change, for the first four weeks of the placement the FE was working elsewhere and supervision had taken place remotely. With location changes, this meant more placement supervision was conducted online than face to face. For the FE, this was no different to many working relationships in an international context, likewise for the student, as their research supervision had been held via Zoom.

In partnership with the school assistant manager (ASM) the student was due to design, develop and deliver training focused on sexual orientation and gender. There is a nascent understanding regarding these issues in Cambodia and this training was planned to launch CFI's team's development of understanding and practice in these areas. Displaying resilience and the ability to manage challenges, the student worked with her Khmer colleague to design an online training session. This was the first time CFI had delivered training in this manner. As part of the training outcomes, the student and ASM requested teams to consider their learning and design a plan to apply this learning to their practice and workplaces. This would be shared with all staff and followed up by the student and ASM. Learning from the training was also measured by the student and ASM designing baseline and end-line questions, which recorded a range of data that illustrated learning achieved and learning still required. Later in the year, practice impact from this training will be measured. This was an innovative piece of practice, displaying the student's knowledge of different cultural groups and sexual orientations. The majority of participants had not considered these issues in depth before, so the student was laying new foundations and enabling new learning.

A further example saw the student engage in research-informed practice and practiceinformed research. The student had been expected to design a case management process for the Education Advocacy (EA) team, focusing on addressing absenteeism at school. This required completing a literature review and gathering data from $\mathrm{C} / \mathrm{Yp}$, parents and schools. As CFI was now only visiting high-risk cases, there was limited access to young people and their parents, so the plan had to be rearranged. Working with 
the EA team, the student created a telephone questionnaire for public school teachers and designed a pathway based on the correlated data. To ensure people who use the service can also be part of this work, the new system will be presented to CFI's Consumer Advocacy group (local parents who offer CFI advice on service development) and to the Student Participation Group, when CFI returns to the office. This is a critically important piece of work as it will direct how CFI supports young people returning to, and remaining at, school. Completing it remotely in this way was not ideal; however, the outcome was still successful and this work will have a direct impact on young people's futures.

Completion of social work Standard Operating Procedures (SOP) from established guidelines was also required. Originally, the student was to spend time with CFI social workers learning how the established guidelines were being put into operation and understanding what detail was required in producing SOPs. Once in Aotearoa New Zealand, the student set regular times to hold online conversations with the social workers, which was far more challenging than it sounds. Working across time zones, cultures, translation, disparities in technology and staff working at home for the first time adds a degree of complexity. Frequently background noise is horrendous as this is not a workforce with quiet studios. Often staff are outside, competing with a range of local noises, from children to motos, to cockerels to dogs and funerals. Considering this, the student felt privileged to be able to undertake this work with a dedicated team, completing SOPs that will direct social work practice for the organisation, and taking the team through each stage as they translated it. This approach improved the learning and understanding of both parties and created a feeling of ownership for the social workers; an amazing achievement.

Interestingly, in this placement, the student took the lead on pieces of complex work for the NGO, work normally undertaken by staff members. There are concerns regarding overseas staff (or students) working in a Global South context being seen as more knowledgeable, simply due to being from the Global North (Fouché et al., 2016). The student needed to remain aware of these sensitivities and ensure all work was undertaken in partnership so that learning for all participants was achieved.

Additionally, the student, FE and university have undertaken placement-based research designed to build upon a 2017 article which explored students' perspectives on the skills, knowledge and capabilities required for international placements (Hay et al., 2017). This updated review measured the impact an overseas student could have on an established workforce and their understanding of required skills, knowledge and abilities in undertaking overseas placements. The student would have held informal conversations with CFI staff regarding these areas. The FE and student held a discussion with the research participants to try and bridge the gap created by the student working remotely. This provided an opportunity to discuss learning achieved from the student's placement and the impact of their absence. This was an important meeting, with the student displaying well-developed communication skills. One conversation compared different ways of working across cultures. A Khmer colleague discussed working in a collective society and that they were learning to be more like the overseas staff-confident in making decisions himself without consulting many people and working independently. The student explained how she, coming from an individualistic society, was learning to be more confident working collaboratively and seeking others' views. This was a fascinating comparison of different cultural practices and shared learning.

\section{Reflections of a student}

The opportunity to complete an overseas placement is a privilege, not one to be taken 
lightly. When completing an international placement, the risks are higher. Any issues hold more weight than at home, where there are more options to fall back on. This is not something actively reflected on before departure; however, relevant areas were considered and prepared for, like emotional support and expectations. CFI is an amazing dedicated NGO with clear direction and purpose and their support of student social workers is inspired. As explained, with preplanning, expectations were clear and many eventualities were considered. What support would there be in-country? Was there an appropriate place to live? How would conflicts be resolved? Five weeks in, when relationships with staff were barely forming, Covid-19 reared its ugly head and a complete reassessment was required. Contingency plans were made and then put into action. There was no doubt the placement would continue, so the attention shifted to how to make it work. For overseas placements, students learn not only about the service and content, but also the subtleties in culture and society that impact practice. No longer being in the country meant this knowledge was more difficult to gain.

More creativity was needed to continue learning about Cambodia, as well as exploring creative ways to convey information and engage with staff online.

Not being present at CFI meant that things took longer; waiting for a reply to an email across time zones and languages rather than walking across the office. This meant increased flexibility, with oneself and others, motivation and heightened communications were also needed. As a distance student, these conditions were not entirely different from study over the past two years. The difference was that the work had real-world consequences and had to be undertaken with others to achieve it.

Being part of a collective society resulted in learning more about working in collaboration, both remotely and in place. Confidence in decisions improved as did learning how to share the reins. Developing the online workshop with the ASM was a great example of this. The student had to combine the ASM's knowledge of local context with an understanding of the issues presented. The balancing act between being comfortable to complete work and allowing space for others' input was made more evident by being apart. Working remotely required more planning, the student had to actively think about how to engage with and involve staff in tasks and therefore, it was more obvious that this process was taking place. For example, in doing the SOP for the social work team, specific meetings focused on work in a shared document. In-country, this activity may have not been so direct. Having focused on collaborative bicultural practice for their research report last year, the student has watched some of those learnings playing out in practice, though in a different context. This was fascinating and will likely influence ongoing practice approaches, for example working more closely with colleagues on cases and projects.

Overall, the most significant impact of Covid-19 and moving back to Aotearoa New Zealand for the remainder of the placement was a lack of contact with Khmer culture and language. A key concern has related to the consideration of local issues, and how to ensure these remain at the forefront of any decision-making. This was certainly made more difficult by not being present, as is evident in the EA research undertaken. The richness of learning that naturally occurs in a foreign context, like casual conversations, daily observations, even observing the subtleties of the language would have influenced the placement in different ways. Having to return home likely resulted in different outcomes both for personal growth and work produced, although it is difficult to say what these will be.

Having to return home was a blow to the stubborn student within. Being acutely aware of their privileges, it was difficult to reconcile contrasting feelings of this situation. Feelings of relief and gratitude stand alongside, and in direct contrast to, 
feelings of deflation and disappointment. Although this placement had to be remoulded and the predicted learning experiences were not to be, it remains a brilliant success. Key learnings included cross-cultural collaboration and further understanding of the inner workings of an international NGO. Furthering research skills and application of theory to macrolevel practice were also developed on this placement. Thanks to the commitment of the FE and CFI staff, the student was given the support needed to complete some useful pieces of work, enriching both CFI services and the student's experience.

\section{Reflections from the university}

International placements are infrequent occurrences in social work programmes in Aotearoa New Zealand. In part, this is due to the significant cost to students with no government funding available to support them to travel, reside, or learn overseas. Also, the Social Workers Registration Board regulations require students to achieve a beginning competence in the core competencies by the end of their qualifying programme and for many programmes, this is largely achieved during the two practicums. Competency one focuses on practice with Māori and therefore this may be challenging to achieve in a meaningful way outside of Aotearoa New Zealand.

Massey University has approved several international placements in the past five years, including a group placement with the University of Waikato in Phnom Penh in 2015. Action research and ongoing reflection about this placement have guided the development of our international placement policy and procedures. Other international placements have been in Australia, the US and Fiji. One of the key learnings from previous international placements relate to the importance of establishing a relationship with the field educator and / or agency prior to confirmation of a placement. This is usual practice for placements in our own country, but can be more difficult and time-consuming for international placements. When we began considering another placement in Cambodia at CFI, a significant advantage was the active relationship we already had with the FE.

International placements often take longer to organise with the student required to complete a specific international placement process. This includes an application wherein the student notes a range of details, including their expected living arrangements, tasks on placement, financial and practical support, cultural considerations, and academic planning. The student also signs a contract for international placements acknowledging that they are, among other things, undertaking the international placement at their own risk and that they are responsible for their personal health and personal safety. Further, they acknowledge they are responsible for having a comprehensive health and travel insurance package that includes repatriation. The university is not liable for any changes made before or during the placement and the student is responsible for registering with the Ministry of Foreign Affairs and Trade. The contract also states that, should an emergency arise, the student should contact the university field education staff as soon as possible.

The approval of an international placement includes the course coordinator, the programme coordinator, the Director of Field Education and the Head of School. The process is robust so as to ensure, as much as possible, the success of the placement. In this particular placement, the planning had taken several months and the university was very supportive of the placement proceeding. The student was confident, mature and capable and there was a strong relationship between university staff and the FE. These characteristics of the student and the placement proved to be critical with the onset of Covid-19.

As news of the virus began to spread in Aotearoa New Zealand, the field education 
staff began to be asked questions, including by the Deputy Vice-Chancellor, about the safety of the student and risk planning. The field education staff addressed the questions and began email correspondence with the student to hear about the situation in Cambodia, their health, and any plans for repatriation. These emails were carefully worded as there was no directive from the university for the student to return home. We did want to convey our support and concern. Several discussions were held amongst staff with varied perspectives on the university's role and whether it could require the student to end the placement if there were not sufficient grounds on which this should be done. Different views on risk management and student autonomy were also discussed with recognition that some staff were more or less risk-averse than others. Consultation was important so that any decision-making did not sit with one staff member. For a large part, we relied on the communication from the student and the FE as we received only minimal media coverage about the virus in Cambodia. We endeavoured to be supportive but allow the student and the FE to determine what would be in the student's best interest. Although not conveyed to the student or the FE at the time, the university staff planned several contingency actions in case the placement was not able to continue. Our primary focus was to ensure the student was safe and would be able to successfully complete her coursework-either in Cambodia or in Aotearoa New Zealand. Several emails were sent and received in the period leading up to the Prime Minister announcing that the country was going to move into Alert Level 4. By this time, the student had left Cambodia and returned to Aotearoa New Zealand, following the government's advice.

This unique situation has given us further opportunity to check the utility of our placement processes for international placements and reinforces the importance of knowing the student well and preferably having a good relationship with the FE. This enables open communication and helps to ensure the focus remains on the student's health, safety, wellbeing and learning.

\section{Reflections of the FE}

The advent of Covid-19 impacted this placement significantly, but importantly the student had the opportunity to complete their course requirements. The student was adaptable, flexible and creative and this made completing the work achievable. There was notable learning from a FE perspective. This experience reinforced that international students need to be resilient and confident as, when something unexpected occurs, there is not an easy escape route. Support and a strong partnership with the university is paramount, with regular consistent communication being required. There is also a sense of responsibility. The FE's decision to leave Cambodia was taken after the student returned to Aotearoa New Zealand, on reflection, the FE realised they could not have left unless the student had already done so. This feeling of responsibility is far more acute than any the FE has experienced with domestic placements and will impact sharply on considerations of future placements.

Any future placements will contain a "government says you need to return home" contingency plan.

\section{Conclusion}

The placement, despite being disrupted, was a tremendous success. The student successfully completed all required tasks and displayed a full range of competencies. The tasks were all significant in terms of the future practice of the NGO. The student was able to gather data, analyse and implement service reviews and developments that will significantly impact the NGO and local community.

What will be interesting is how this experience may impact future overseas opportunities. Of consideration is whether a student has to be overseas to complete a placement within an overseas organisation, especially now that our "new normal" has an unknown end date. 


\section{References}

Children's Future International. (2020). What we do. Retrieved from https://www.childrensfuture.org/what-we-do/

Cooner, T. S. (2010). Creating opportunities for students in large cohorts to reflect in and on practice: Lessons learnt from a formative evaluation of students 'experiences of a technology-enhanced blended learning design. British Journal of Educational Technology, 41(2), 271-286.

Fouché, C., Beddoe, L., Bartley, A., \& Parkes, E. (2016). Are we ready for them? Overseas-qualified social workers' professional cultural transition. European Journal of Social Work, 19(1), 106-119.

Fronek, P., Common, R., Smith Rotabi, K., \& Statham, J. (2019). Identifying and addressing risk in the implementation of alternative care policies in Cambodia. Journal of Human Rights and Social Work 4(2), 140-144 https://doi.org/10.1007/s41134-018-0087-y

Hay, K., Lowe, S, Barnes, G., Dentener, A., Doyle, R., Hinii, G., \& Morris, H. (2017). "Times that by 100": Student learning from international practicum. International Social Work 61(6), 1187-1197. https://doi.org/10.1177/0020872817702707

Henley, L., J., Lowe, S., Henley, Z. A., Munro, C. (2019a). Overseas social work placements: Can a well-designed workflow increase the success of an overseas placement? Aotearoa New Zealand Social Work, 31(2), 69-76.

Henley, L. J., Lowe, S., Henley, Z. A., Munro, C., Chan, C., Chhong, C., ... L. Song (2019). International social work placements: Can overseas students stimulate professional learning for NGO staff? Advances in Social Work and Welfare Education, 21(1), 84-99.

Peterson, L. (2014). Using technology in peer role-play assignments to enhance competency in clinical dyadic treatment: A pilot study. Journal of Technology in Human Services, 32(1-2), 4-21. https://doi.org/10.1080/152288 35.2014 .885403

Save The Children International. (2019). Family Care First / REACT, Family strengthening: A collection of promising practices. International Child Development Initiatives. Retrieved from https://www.childrensfuture.org/ wp-content/uploads/2020/01/FCF-REACT-PromisingPractices-Review_FINAL-1.pdf

Wehbi, S. (2011). Reflections on experiential teaching methods: Linking the classroom to practice. Journal of Teaching in Social Work, 31(5), 493-504. https://doi:10.1080/08841233.2011.614205

World Health Organisation. (2020). Coronavirus. Retrieved from https://www.who.int/health-topics/ coronavirus\#tab=tab_1 